\title{
SOBRE AS COMPULSÕES E O DISPOSITIVO PSICANALÍTICO
}

Jô Gondar

Psicanalista, professora adjunta do Departamento de Filosofia e Ciências Sociais da UNI-Rio. Membro do Espaço Brasileiro de Estudos Psicanalíticos.
RESUMO 0 artigo se insere numa pesquisa mais ampla acerca das novas formas de padecimento psíquico que se apresentam na atualidade. Essas formas, que têm na compulsão uma figura-ti po, colocam em xeque a modal idade de escuta, de entendimento teórico e de intervenção clínica do psicanalista. Discutimos aqui os principais impasses trazidos por esses pacientes ao dispositivo psicanalítico, procurando nele apontar algumas possibilidades de abertura ou transformação.

Palavras-chave: compulsão, subjetividade, dispositivo psicanalítico.

ABSTRACT On the compulsions and the psychoanalytical setting.The article is part of a wider research about the new forms of psychical suffering as they appear in our present time. Those forms - compulsion is their prototype - inquire the psychoanalytical way of listening, of theoretical understanding and of clinical intervening. It is discussed here the main problems brought to the psychoanalytical setting by those patients, looking for some possibilities of opening or transformation.

Keywords: compulsion, subjectivity, psychoanalytical setting.

Qartleby, o escriturário, personagem de uma famosa novela DeHerman Melville, responde às ordens de seu chefe sempre com a mesma frase, pronunciada de forma cal ma e serena: "Preferiria não." Não faz nenhuma objeção às tarefas ou às regras do escritório; ele apenas as recusa, passiva e progressivamente. Prefere não executar as tarefas para as quais foi contratado, preferenão sair do escritório fora do horário de trabalho e, após levar todos à exasperação - a ponto de mudarem de en-

* Versão ampliada do trabal ho apresentado no Encontro Latino-Americano dos Estados Gerais da Psicanálise, realizado em São Paulo, em $13 / 10 / 2001$. 
dereço para impedir a sua presença - é conduzido à prisão, onde prefere não falar, não andar e não comer, recusando-se, no limite, a viver. A despeito deste "não" que se repete e se alastra, Bartleby poderia ser descrito como um homem sem qualidades, ou, melhor, um homem que, no decorrer da história, despe-se progressivamente delas. Não aparece em seu "preferiria não" o colorido de um desejo, de uma fantasia ou de um conflito, capazes de situar esta recusa ${ }^{1}$ como afirmação de um território subjetivo. Na verdade, Bartleby parece vazio de subjetividade: uma figura de homem genérico e tão próximo de uma universalidade nua que sua recusa, na ausência de qual quer colorido desejante, só pode conduzilo à autodestruição, ao invés de tornar-se uma alternativa singular e viável. ${ }^{2}$

Qual a razão de introduzirmos a personagem de M elville num trabalho sobre as compulsões? Se Bartleby se recusa a agir, e se as compul sões são patologias do ato, não estaríamos incorrendo num contra-senso? Recomecemos então a partir de uma outra ilustração na qual o ato ocupa o primeiro plano para, em seguida, esclarecer em que medida os dois exemplos nos permitem avançar no debate sobre as compulsões.

N um artigo publicado recentemente na Folha deS. Paulo, Slavoj Zizek comenta o caso da texanaAndreaYates, ocorrido em junho deste ano. Considerada mãe exemplar, a ponto de deixar seu emprego de enfermeira para dedicar-se exclusivamente aos filhos, e tendo colocado sua vida sempre a serviço dos outros, Andrea surpreende a todos com um ato terrível: num dia comum, após a saída de seu marido para o trabalho, ela enche a banheira e afoga uma a uma suas cinco crianças, entre seis meses e 7 anos - crianças que, muito provavelmente, a olhavam perplexas durante a metódica operação. Em seguida, ela chama a polícia e o marido, afirmando muito calmamente: "matei meusfilhos". Não há muitas dúvidas deque se trata de uma passagem ao ato, e a hipótese de Zizek é a de que esse ato surgiria como resposta a um imperativo cujo cumprimento é impossível. Não pretendemos discutir aqui a pertinência de uma hipótese sobre um processo subjetivo baseada meramente em informações jornalísticas, como ocorre no citado artigo. Para o que nos interessa, gostaríamos apenas de enfatizar a injunção que, segundo Zizek, estaria na raiz da passagem ao ato: "seja feliz e encontre sua realização dentro do inferno de sua casa, onde seus filhos a bombardeiam com exigências impossíveis de serem satisfeitas e onde todas as suas esperanças são frustradas" (ZIZEK, 2001). A hipótese é a de que a mãe se encontraria num impasse, num dilema decorrente da própria exigência de um gozo impossível. Diante desta, sua única

\footnotetext{
10 termo "recusa", aqui, deve ser tomado da língua corrente, não estando associado ao conceito freudiano de Verleugnung.

2 Esta personagem de Melville mereceu uma acurada análise de Gilles Deleuze (1997). As implicações políticas da recusa de Bartleby foram enfatizadas por Michel Hardt e Antonio Negri (2001).
} 
saída foi a de destruir os seres que encarnariam a injunção cruel e obstinada, e a sua própria condição de maternidade.

Nesses dois exemplos, um tirado da ficção e outro da vida real, o que há em comum é uma modalidade de recusa que não oferece lugar ao desejo. É verdade que em Bartleby esta recusa se dá sob a forma de uma quase petrificação, enquanto que na mãe ela conduz ao mover-se eao agir. Em ambos os casos, contudo, há uma recusa a obedecer as injunções, mas realizada de forma vazia, estando ausentes os argumentos ou atos que poderiam efetivamente fazer objeção aos mandamentos. É como se diante de uma lei experimentada como imperativo categórico - imperativo que não leva em conta os prazeres, desejos e inclinações singulares - a resposta do indivíduo fosse uma recusa igualmente categórica, uma desobediência que conduziria, paradoxalmente, à obediência do imperativo, na imposição de manter o desejo fora do campo. Por esse motivo, os atos de desobediência desse tipo flertam continuamente com o abismo e a autodestruição. Deleuze os chama de linhas de fuga suicidárias, devido à impossibilidade de se constituírem como uma alternativa real, para além da pura e cega recusa.

Pensamos que este modo de dizer não a uma lei experenciada como tirânica e inegociável se encontra presente naquilo que se convencionou chamar de "novos sintomas", ainda que possamos perguntar se eles são, de fato, tão novos assim. À primeira vista, o que nos surpreende nesses distúrbios psíquicos - implicados na bulimia, anorexia, alcoolismo, toxicomania, fenômenos de pânico e disposições melancólicas - éa sua freqüência na cultura e, conseqüentemente, na clínica atual, a ponto de constituírem uma espécie de figura-tipo da contemporaneidade. E o que está em questão, nessa figura-tipo, é a esfera do ato. Em outros termos: trata-se de formas de padecimento que podem ser consideradas patologias do ato, tanto na sua vertente de inibição quanto na de realização. ${ }^{3}$ Por este motivo, o problema das compulsões ganha tanta importância na atual idade: nelas, a patologia do ato aparece em sua forma mais nítida.

Com efeito, o sujeito contemporâneo poderia ser descrito como um sujeito compulsivo, sem que se possa situá-lo numa estrutura clínica definida. Sujeito? Com relação às compulsões, tal vez fosse melhor falarmos em atos aos quais não se associa um sujeito capaz de por eles se responsabilizar ou se engajar em suas conseqüências. Ora, as compulsões não são um elemento novo na psicanálise. Mas até agora costumávamos tratá-las como fenômenos pontuais no funcionamento psíquico. 0 queé novo, o que nos surpreende, não é apenas o aumento da freqüência destesfenômenos, mas a abrangência que conquistam em al guns territórios subje-

\footnotetext{
${ }^{3} 0$ problema das compulsões, no que diz respeito aos "novos sintomas", tem sido trabal hado por Romildo Rêgo Barros no seminário sobre "Obsessão", atualmente desenvolvido na Escola Brasileira de Psicanálise, a partir de uma hipótese distinta da que apresentamos. Algumas das idéias em construção nesse seminário estão sendo aqui utilizadas.
} 
tivos, cujos marcos se delineiam de forma bastante diversa da vel ha e boa histeria, para a qual o dispositivo psicanalítico foi criado. Desse modo, as compulsões têm desafiado os psicanal istas e levado sua prática a um impasse, obrigando-os a repensar sua modalidade de escuta, de entendimento teórico e de intervenção clínica, obrigando-0s, enfim, a reconstruir um dispositivo capaz de acolher etrabal har essa forma de funcionamento psíquico. Tentaremos aqui mapear al gumas dessas mudanças, a partir da hipótese que apresentamos - a compulsão como tentativa ( ainda que fracassada) de dizer não ao imperativo superegóico. Antes, porém, a hipótese precisa ser explicada, e esclarecidos os el ementos em jogo. Vamos então partir das compulsões, conforme foram teorizadas por Freud.

Dissemos já que a compulsão não é um fenômeno novo na psicanálise. É sob dois modos principais que el a se apresenta na obra de Freud. Por um lado, a compulsão (Zwang, em alemão) remete diretamente à neurose obsessiva (Zwangneurose), ainda que, no interior desse quadro, ela apresente matizes. $N$ as explicações que Freud apresenta sobre essa neurose, compul são não é simplesmente sinônimo de obsessão, mas diz respeito a uma peculiaridade de determinados sintomas obsessivos: trata-se de pensamentos ou atos que o sujeito realiza ainda que Ihe pareçam um corpo estranho, pensamentos ou atos movidos por uma força irresistível contra a qual o sujeito gostaria de lutar. A compul são, nesse caso, resulta de um conflito psíquico e de uma luta subjetiva entre duas injunções opostas, estando o sujeito impossibilitado de escolher qualquer uma delas. Encurralado nessa hesitação exasperante, a resposta do sujeito é o ato compulsivo - Freud o considera uma compensação da dúvida - que se produz como uma espécie de "vazamento" : a imagem aqui seria a do suco de uma fruta que, de tão espremido, acabaria escoando pelos cortes feitos na casca (HANNS, 1996).

Mas a compulsão tem em Freud um outro sentido importante: Zwang alude também ao que há de mais radical na pulsão, isto é, sua irrefreável repetição. Mas, diferentemente dos atos compulsivos do neurótico obsessivo, a compulsão à repetição (W iederholungšwang) não poderia ser encarada como o resultado de um conflito, motivo pelo qual não é necessariamente experenciada, por quem a sofre, como expressão de uma luta íntima. Trata-se, na verdade, de uma característica fundamental da própria pulsão, logicamente anterior ao estabelecimento de um conflito pulsional, ainda que essa anterioridade a torne o motor de todo conflito e de toda formação psíquica. Grosso modo, poderíamos caracterizar a compulsão à repetição como um impulso avassalador ao qual sucumbe o sujeito, que passa então a justificá-lo por contingências da atualidade: é como se ele tentasse organizar o impulso cego segundo os ditames de uma "cena”, buscando conteúdos capazes de preencher uma forma vazia, autônoma, e, em última instância, irredutível aos seus próprios conflitos.

Pensar as compul sões contemporâneas nos obrigaria a manter esse segundo 
sentido - já que o que as move é a repetição pulsional; em contrapartida, deveríamos distingui-las do primeiro: não se trata de idéias ou atos compulsivos, tais como se apresentam na neurose obsessiva. Tudo indica que, nesta última, a compulsão implica um caminho mais longo, envolvendo elementos psíquicos mais complexos: encontram-se em jogo dois mandamentos opostos - funcionando como ordem e contra-ordem - diante dos quaiso indivíduo se vê num estado de hesitação, de dúvida, produzindo-se assim um intervalo de tempo no qual a compulsão não ocorre (AM ORIM e SANT'AN NA, 1999). Por meio desta hesitação, o obsessivo relativiza a obediência cega ao mandamento, mantendo, ao mesmo tempo, a crença de que seria possível escolher simultaneamente a possibilidade a e a possibilidade b, ou, mais rigorosamente, que seria possível não escolher nem a nem $b$, para não ter que pagar o preço que se impõe a qualquer escolha. É justamente esse elemento de hesitação, fazendo obstáculo à obediência do mandamento, que se encontra ausente nas compulsões contemporâneas. É como se fosse aí eliminado o intervalo de tempo que a dúvida impõe a este processo, produzindose então a compulsão por um caminho mais curto: à injunção impossível se segue diretamente, em resposta, a passagem ao ato (Idem).

Quando falamos em realização pelo caminho mais curto, somos remetidos à pulsão de morte ou, mais exatamente à prática de um gozo destrutivo. 0 psicanalista que trabalha com compulsivos não demora a notar o quão fortemente se apresenta, nesses pacientes, a aliança entre o supereu e a pulsão de morte, redundando numa forma cruel de injunção superegóica: ao invés de funcionar como barreira a um gozo mortífero, o supereu o exigiria, desprezando por completo a esfera das inclinações subjetivas singulares. Tal qual o imperativo categórico formulado por Kant, o mandamento do supereu ordenaria que o sujeito abdicasse de sua dimensão desejante, agindo única exclusivamente por dever. 0 que implica, em termos psicanalíticos, que o sujeito se coloca como objeto de gozo a serviço de uma lei cruel. Este carrasco íntimo é a grande personagem dos funcionamentos compulsivos. 0 que queremos ressaltar, todavia, é que as compulsões não se reduzem a uma pura e simples obediência ao imperativo superegóico, que os compulsivos não são figuras da moral kantiana, e que o empuxo ao gozo não pode ser diretamente traduzível pelas ordens: coma, beba ou drogue-se. Pensamos, ao contrário, que os atos compulsivos são uma tentativa de fazer obstáculo ao cumprimento da injunção cruel, ainda que essa tentativa fracasse: há neles um lampejo de subjetivação que não chega a efetivar-se como afirmação de desejo.

Quais são os impasses trazidos por esse modo defuncionamento ao dispositivo psicanalítico tradicional? Façamos aqui uma espécie de descrição clínica do paciente que apresenta patologias do ato, tentando apontar, a partir dela, algumas mudanças que se impõem ao dispositivo. Não é demais lembrar que se trata da descrição de uma figura-tipo, podendo ser matizada conforme as modalidades 
subjetivas singulares: raramente se verá uma configuração pura de "novos sintomas" sem que aí também se mesclem as formações sintomáticas mais conhecidas; caberá à acuidade do analista distinguir a lógica subjetiva predominante numa determinada situação.

U ma das maiores dificuldades encontradas na clínica desses pacientes reside na relação que estabelecem com seus sintomas, tornando-os inacessíveis à interpretação. Em seu sentido clássico, um sintoma é uma formação de compromisso entre uma instância recalcada e uma instância recalcante, por meio da qual o inconsciente se expressa. 0 que significa dizer que esse sintoma fal a, representando um sujeito e revelando algo sobre o seu desejo. Na situação analítica clássica, 0 paciente chegaria à análise queixando-se de seu sintoma; a partir disso poderia construir uma questão sobre si mesmo, endereçando-a ao analista. Com base nesta questão e neste endereçamento, seria possível formular-se, no campo transferencial, uma interpretação, produzindo-se uma verdade a respeito do desejo.

Ora, toda essa lógica cai por terra diante dos modos contemporâneos de subjetivação. Em primeiro lugar, esses pacientes chegam ao consultório apresentando sintomas que não se endereçam a um Outro, nem como forma de se situarem subjetivamente, nem sob a forma de queixa - "a culpa é de meu pai ou de minha mãe", por exemplo - , nem sob a forma de pergunta dirigida ao analista. Raras vezes esses indivíduos, a partir de seus sintomas, se colocam em questão ou produzem associações. Tudo se passa como se seu sofrimento fosse da ordem de uma fatal idade que não inclui um outro, uma fatalidade que a eles se impinge sem matizes, como um monolito do qual eles pouco têm a dizer. Os discursos esvaziados de desejo são freqüentes, tanto faz que se expressem de maneira monocórdia ou, ao contrário, tonitruante - o forte colorido pulsional, neste último caso, não chega a definir um desejo, funcionando como uma espécie de linha monocórdia ao avesso. São discursos nos quais também se nota a ausência de um semelhante reconhecido enquanto tal, com o qual o paciente é capaz de identificar-se; trata-se, na verdade, de indivíduos com pouca disposição para a rivalidade, inveja ou competição, ou seja, indivíduos que não se encontram capturados pel os jogos de dualidade narcísica, pela lógica do "ou eu ou o outro". Essa ausência de coordenadas imaginárias se ancora numa relação com a lei bastante singular, fomentando uma constante sensação de estranheza e de não-pertencimento, nem sempre claramente enunciada: uma das grandes fontes de sofrimento para esses pacientes reside no fato de sua própria realidade e a do mundo Ihe parecerem profundamente discordantes, como se houvesse um hiato irredutível entre as regras que fazem o mundo funcionar eaquelasqueorganizam o seu próprio funcionamento (GONDAR, 1998).

Os sintomas compulsivos não podem ser considerados simplesmente como manifestações do inconsciente ou formações de compromisso. Dificilmente poderíamos pensar que 0 ato compulsivo de beber ou drogar-se, por exemplo, esta- 
ria representando um sujeito, ou dizendo algo sobre um desejo inconsciente. Esses sintomas não se produzem a partir de uma operação de recalcamento, ou melhor, não consistem num retorno do recalcado; el es se formam por um caminho mais curto, no qual uma satisfação pulsional, com forte tonalidade destrutiva, se exerce mais diretamente. Por este motivo, estes sintomas resistem, como 0 azeite à água, à intervenção clássica da clínica psicanalítica - a interpretação. Lembremo-nos aqui das interpretações que Freud dirigia às suas histéricas: eram intervenções que procuravam revelar o sentido oculto de seus sintomas, apontando a verdade do desejo que por eles se expressava; as interpretações tinham por objetivo oferecer um pano de fundo fantasmático a partir do qual os sintomas poderiam ser situadosno plano do sentido.

Todavia, não existe um pano de fundo fantasmático a partir do qual se possa ler as compulsões - ou o pânico, ou as atuações que alguns denominam contrafóbicas. Na verdade, o que aí se encontra em falta é justamente essa tela protetora que articula as relações entre a subjetividade e o real. Faltam a fantasia e seus derivados - crenças, projetos, ilusões. Esses indivíduos apresentam uma fal ha brutal na dimensão do imaginário, expressando-se em todos os níveis: na fantasia, na constituição de um semelhante, na constituição da própria imagem corporal. É como se o corpo fosse reduzido a uma matéria da qual eles são meros portadores, criando-se a necessidade de próteses de sustentação egóica, encontradas al gumas vezes através de exercícios físicos ou de adereços que rasgam a pele. A ausência de fantasi a os lança, sem mediação, diante de uma diferença absoluta: esses pacientes parecem se encontrar ante o olhar siderante de Gorgó, a Medusa, recebendo uma luz e uma lucidez capazes de levar à cegueira e à petrificação. Seria preciso um outro olhar que pudesse fazer barreira à sideração que os petrifica: o olhar do anal ista mostra-se, nesses casos, fundamental para promover uma costura do tecido esgarçado, favorecendo a construção de uma tela fantasmática e da própria imagem corporal - por esse motivo, não é recomendável indicar-Ihes o divã. Diante de tal funcionamento, não é de se estranhar que as interpretações, comumente pautadas na desconstrução do imaginário, tornem-se aqui inoperantes, em sua tentativa de partir o que já está fragmentado, ou de desmontar aquilo que, ao contrário, precisaria ser construído.

Mas existe uma outra esfera na qual a interpretação não surge apenas como ineficaz: ela se torna perigosa. Com efeito, a fal ha no registro imaginário se articula à relação especial que esses indivíduos estabelecem com a lei. Para eles, a lei não pôde ser subjetivamente construída; ela se impõe sob moldes kafkianos, sem receber o revestimento imaginário que poderia lhe fornecer um sentido particular o que ocorre, por exemplo, quando cremos que a lei é capaz de nos proteger, ou que podemos evitar as agruras do acaso se cumprimos de modo satisfatório as regras que ordenam as relações entre os homens. Não havendo uma subjetivação 
da lei, esta se apresenta ao indivíduo em toda a sua crueza e arbitrariedade: pareceIhe que aquilo que a lei proíbe évetado em si mesmo, de forma violenta e inexplicável; do mesmo modo, parece-lhe que aquilo que a lei obriga se torna uma fatalidade inexorável. Em muitas situações, esses pacientes demonstram um excesso de lucidez: é como se incessantemente lhes fossem revel ados a arbitrariedade e 0 sem-sentido da lei, impossibilitando qual quer ilusão de amparo ou garantia.

Ora, a forma clássica da interpretação não apela simplesmente para a desconstrução do imaginário; ela se exerce sob a forma de um corte cuja lógica éa da lei da castração. Mas foi justamente esta que não pôde ser subjetivada por esses pacientes. A forma da lei por eles conhecida é a que se apresenta sob forma tirânica, cruel: a lei superegóica. Sendo assim, qualquer intervenção do analista que tome por fundamento a lei da castração será traduzida por esses indivíduos nos termos de uma outra lógica, aquela que os acossa: as interpretações funcionarão, nesse caso, como palavras persecutórias de ordem, fortalecendo o mandamento superegóico.

M as estando descartada a interpretação, que modalidade de intervenção clínica seria eficaz, no campo psicanalítico? Pensamos que na direção do tratamento dos pacientes compulsivos, algumas condições, mutuamente implicadas, são requeridas: o esvaziamento do imperativo superegóico, fonte propiciadora de seus sintomas; a constituição de uma esfera imaginária e fantasística; e, o mais importante, a assunção da dimensão desejante, comumente esmagada pelo supereu cruel. Neste ponto a sensibilidade clínica e a disposição para o risco, por parte do anal ista, são radicalmente convocadas: como criar as condições para que o desejo se afirme, quando não há desejo?

Tal vez seja preciso, antes de tudo, colocarmos em questão uma categoria que tem sido muito cara à psicanálise. Referimo-nos à categoria de sujeito. Pois ela, de fato, não nos permite avançar no entendimento e no tratamento das contemporâ neas patologias do ato. Ao mantermos essa noção, o que mais poderíamos fazer senão admitir que estamos diante de sintomas nos quais, estranhamente, o sujeito não comparece, o desejo não comparece, e onde não há Outro? N esse caso, o psicanalista se veria numa situação sem saída, tornando-se muito difícil apontar uma direção de tratamento com relação a esses pacientes, que tampouco podem ser situados numa estrutura clínica definida. Porém, se as categorias circunscritas forem substituídas por noções mais móveis, processuais - como as de modos de subjetivação, por exemplo - aquilo que se apresentava como um impasse torna se o próprio ponto de partida do tratamento. Em outros termos: admitir que existem nas compulsões lampejos de subjetivação - algo bem distinto de postular que aí não há sujeito - implica admitir um campo subjetivo com maior extensão e plasticidade, a partir do qual podemos trabalhar, processualmente, na direção do desejo - sem desmerecer o nosso compromisso enquanto psicanalistas. Mais do 
que abandonar a idéia de sujeito e seus derivados, trata-se de inseri-las num terreno mais vasto, capaz de abarcar diversas modulações possíveis de subjetivação.

Retornemos então à hipótese que apresentamos sobre as novas formas de padecimento: dissemos que as compulsões seriam tentativas de dizer não ao imperativo superegóico, sem que, contudo, pudessem demarcar positivamente um território subjetivo. Por elas se expressaria um lampejo de subjetivação que não pôde configurar-se como afirmação de desejo. Contudo, ao valorizarmos as noções móveis e processuais, somos levados a reconhecer que, ainda que não haja desejo, existe aí um índice, uma fagulha, um lampejo desejante que serviria de apoio a um trabaIho de construção, a partir do qual uma negação sem consistência poderia transmutar-se em afirmação. Trabalho delicado, árduo, persistente: seria preciso inserir atritos num caminho liso, possibilitando o incremento de matizes, velamentos e ligações onde a satisfação pulsional costumava se exercer num circuito mais direto. N esse caso, as tonalidades pulsionais - encaradas como parte de um processo de subjetivação - tornam-se a própria matéria a partir da qual se exerce um trabalho.

Se trazemos as expressões pulsionais para o primeiro plano, considerando-as virtualidades desejantes, a escuta e as interven ções do analista precisarão expandir-se, mostrando-se distintas da mera escuta de palavras ou da produção de interpretações que inflam o supereu. Tornam-se extremamente importantes a esfera do ol har e da voz, agindo mais diretamente no campo pulsional. Da mesma maneira, é preciso que 0 analista esteja atento às modalidades expressivas do paciente, aos brilhos e sombras do olhar, às suas modulações de voz ou gestuais. Não para fornecer a elas uma interpretação, mas para discriminar através del as os momentos em que pequenas inflexões de desejo são capazes de se colocar em jogo.

Sob que bases poderíamos compreender esses ínfimos movimentos desejantes? Neste ponto, devemos recorrer a outros campos de conhecimento nos quais essa experiência tem sido teorizada. 0 filósofo José Gil, dedicando-se à experiência estética (GIL, 1996) , retoma de Leibniz a noção de "pequenas percepções" , noção que, para ele, não se aplicaria apenas à apreensão de uma obra de arte, mas a todos os "fenômenos de limiar", aí incluindo-se a transferência analítica. As pequenas percepções nos permitiriam valorizar as intensidades que extrapolam o domínio significante, intensidades que se mostram presentes no tom e ritmo da voz, na expressão do rosto, no tônuse postura corporal, bem como em al guns ruídos que o indivíduo produz sem perceber. Ao trazer essa noção para a clínica psicanalítica, Eliana Schueler Reis (REIS, 2000), nos propõe que a "atenção flutuante" não se reduza à escuta, e que inclua também o que é percebido por um "olhar flutuante" ${ }^{4}$ capaz de apreender pequenos gestos e atos que não estariam indicando uma

\footnotetext{
${ }^{4}$ Expressão criada por Eliana S. Reis a partir da proposta de José Gil.
} 
cena fantasmática ou uma representação recalcada; para aquém destas, eles seriam um índice de impressões que não se registraram como traços, mas que, todavia, buscam um caminho para se manifestar.

Caberia ao analista valorizar esses "fenômenos de fronteira" como lampejos de subjetivação, apreendendo-os através das "pequenas percepções" que, para José Gil, implicam na dissolução da percepção costumeira, objetivadora. Trata-se, portanto, de levar ainda mais longe a atenção flutuante, envolvendo uma maior disposição do anal ista para abster-se da condição de sujeito, nela incluindo também 0 seu campo particular de percepções, normalmente selecionado segundo as significações que valoriza. Este refinamento perceptivo acolheria de modo mais pregnante os signos de subjetivação que ainda não instituíram como traço, signos que se manifestam através de imagens ou expressões fugidias, aparentemente inócuas, e dificilmente notadas pela percepção corrente. Sobre a base desses signos, todavia, poderiam ser construídas as relações transferenciais.

No tratamento dessas novas formas de padecimento, o campo transferencial seria convocado para propiciar um traçado de consistência aos lampejos de desejo, aqueles que o supereu não foi capaz de submeter de todo. É neste campo que as ínfimas manifestações desejantes podem encontrar uma possibilidade de expressão e de articulação, um reconhecimento e uma legitimidade. A legitimidade torna-se aqui uma questão essencial, tratando-se de indivíduos que, al ijados do direito ao desejo pelo imperativo superegóico, passam a desconhecer ou desmerecer, desde a raiz, suas próprias tentativas de exercê-lo. A fineza e delicadeza da escuta e do olhar buscariam, nesses casos, fazer ressoar e persistir os pequenos movimentos de subjetivação, fornecendo consistência ao desejar. 0 que aqui se coloca em pauta não é a desconstrução do dispositivo psicanalítico, mas a sua ampliação: seria preciso tornar mais finas e mais complexas as regras da associação livre e da aten ção flutuante, bem como a proposta de abstenção do analista, a fim de que possam abarcar essas novas modal idades subjetivas.

Contudo, tal ampliação do dispositivo não deixa de ter conseqüências políticas. Voltemos agora à personagem de M elville, o escriturário Bartleby: sua recusa é vazia, seu não às injunções é solitário, faltando-Ihe a consistência desejante que poderia transmutá-lo em afirmação de um modo de vida. Como dizem Toni Negri e Michel Hardt, em seu recém-publicado Império:

“Em termos políticos (...) a recusa em si leva apenas a uma espécie de suicídio social (...) 0 que precisamos é criar um novo corpo social, projeto que vai além da recusa. N ossas linhas de fuga, nosso êxodo precisam ser constituintes e criar uma alternativa real." (NEGRI \& HARDT, 2000, p. 224)

No campo subjetivo, a clínica psicanalítica é parte essencial na criação dessas 
alternativas, pois elas só o são na medida em que se articulam ao desejo. E se nele reside o compromisso dos psicanal istas, seu trabalho com as novas formas de subjetivação passa a exigir mais persistência e mais delicadeza. Talvez nos animem as palavras do poeta: "Onde não hájardim, as flores nascem de um secreto investimento em formas improváveis." 5

Recebido em 10/ 10/ 2001. Aprovado em 12/ 11/ 2001.

\section{BIBLIOGRAFIA}

AMORIM, L. e SANT'AN NA, M.A.M. "A compulsão de comer", in Ágora, v. II, n.1, jan/ jun, Rio de Janeiro, UFRJ/ Contra-Capa, 1999.

DELEUZE, G. Crítica e clínica, São Paulo, Editora 34, 1997.

GIL, J. A imagem nua e as pequenas percepções - estética emetafenomenologia, Lisboa, Relógio d'Água, 1996.

GONDAR, J. "A fobia e o véu rasgado" in Ágora, v. I, n.1, jul/ dez, Rio de Janeiro, UFRJ/ Contra-Capa, 1998.

HANNS, L. Dicionário comentado do alemão de Freud, Rio de Janeiro, Imago, 1996.

HARDT, M. e NEGRI, A. Império, Rio de Janeiro, Record, 2001.

REIS, E. S. "De corpos, atos, afetos e palavras", tese de doutorado em Saúde da Criança e da Mulher, defendida no IFF/ Fiocruz, 2000.

ZIZEK, S. "Violência emancipadora" in Folha de S. Paulo, São Paulo, Caderno Mais, 19 de agosto de 2001.

Jô Gondar

RuaVisconde da Graça, 213/ 401

22461-010 Rio de Janeiro RJ

Telefax (21)2511-1991

E-mail: jogondar@uol.com.br

${ }^{5}$ Trata-se de um verso do poema "Campo de flores", de Carlos Drummond de Andrade. 